\title{
DESIGN AND DEVELOPMENT OF AUTOMATIC PNEUMATIC BUMPER AND BREAKING SYSTEM
}

\author{
D. Manimegalai \\ Asst. Professor \\ Department of Electrical and Electronics Engineering, \\ Vel Tech, Chennai, India, \\ S. Preetha \\ U.G. Student, Department of Electrical and Electronics \\ Engineering, Vel Tech,Chennai, India,
}

\begin{abstract}
Now-a-days, pneumatics plays a major role in the field of automation. Our work plan is to develop a control system based electronic controlled automatic bumper and braking activation system. This system consists of ultrasonic based transmitter, ultrasonic receiver, control unit, pneumatic bumper and pneumatic braking system. The ultrasonic sensor senses the obstacle (within 3 feet) and sends signal to the control unit. User can select the activation system of brake and bumper using Keypad depending on their requirement. When an obstacle is detected, the sensor through control unit activates the bumper and braking system.
\end{abstract}

Keywords- Ultrasonic transmitter, Ultrasonic receiver, Bumper, control unit, ultrasonic sensor, pneumatic braking system, control system.

\section{INTRODUCTION}

We are delight in introducing our project "AUTOMATIC PNEUMATIC BUMPER AND BRAKING SYSTEM" which consists of Ultrasonic sensor and Pneumatic bumper and braking activation circuit. It is fully equipped and designed for automobile vehicles. Many road accidents are caused by humans. There are different reasons for these accidents but proper technology of braking system and technology to reduce the damage during accident are mainly affecting on the accident rates. So, we need to implement a proper braking and bumper system to prevent the accidents is necessary. To achieve this, we need to design this Automatic Braking with Pneumatic Bumper system(Aung 2018; Brännström et al.,2014; Cho et al.,2016).

\author{
S. Megha Shamini \\ U.G. Student, Department of Electrical and Electronics \\ Engineering, Vel Tech,Chennai, India,
}

\section{G. Reshma}

U.G. Student, Department of Electrical and Electronics Engineering, Vel Tech, Chennai, India,

\section{PNEUMATICS}

'Pneumatikos', meaning 'coming from the wind.' Pneumatics is the study that makes use of gas or pressurized air. The Pneumatic system works on a supply of compressed air which is to be had in sufficient quantity and at a pressure to fit the capacity of the system. The key part of any facility for supply of compressed air is by means using reciprocating compressor. A compressor is a machine that takes in air, gas at a certain pressure and delivered the air at a high pressure. Compressor capacity is the actual quantity of air compressed and delivered and the volume expressed is that of the air at intake conditions namely at atmospheric pressure and normal ambient temperature ( H. 2019; katarkar et al., 2017; Lee, 1976; Pavan Kumar et al., 2018).

The Robert Boyle investigates the first compressibility of the air in 1962 and the formulae for compressibility of the air are given by the product of pressure and volume of a quantity of gas. The usual written as (Rahate, 2018; Rane et al., 2017; Sai et al., 2019; Suryawanshi et al., 2017; T and O, 2014).

$\mathrm{PV}=\mathrm{C}$ (or) $\mathrm{P}_{1} \mathrm{~V}_{1}=\mathrm{P}_{2} \mathrm{~V}_{2}$

In this equation the pressure is the absolute pressured which for free is about 14.7 Psi and is of courage capable of maintaining a column of mercury, nearly 30 inches high in an ordinary barometer. Any gas can be used in pneumatic system, but air is the mostly used system now a days. The term 'pneumatic' is based on the Greek word (Wada et al., 2010).

\section{UltRASONIC SENSOR}

Ultrasonic sensors are utilized to distinguish the nearness of targets and to gauge the separation to focuses in numerous robotized preparing plants and procedure plants. Sensors with an $\mathrm{ON}$ or OFF advanced yield are accessible for distinguishing 


\section{International Journal of Engineering Applied Sciences and Technology, 2020 \\ Vol. 4, Issue 12, ISSN No. 2455-2143, Pages 305-309 \\ Published Online April 2020 in IJEAST (http://www.ijeast.com)}

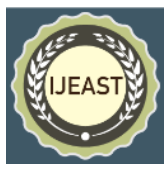

the nearness of articles and sensors with a simple yield which changes moderately to the sensor to target partition separation are financially accessible. Ultrasonic sensors measure separation by utilizing sound waves. The sensor head transmits the soud waves and gets the wave reflected over from the objective. They measure the separation to the objective by estimating the time between the emanation and the gathering.

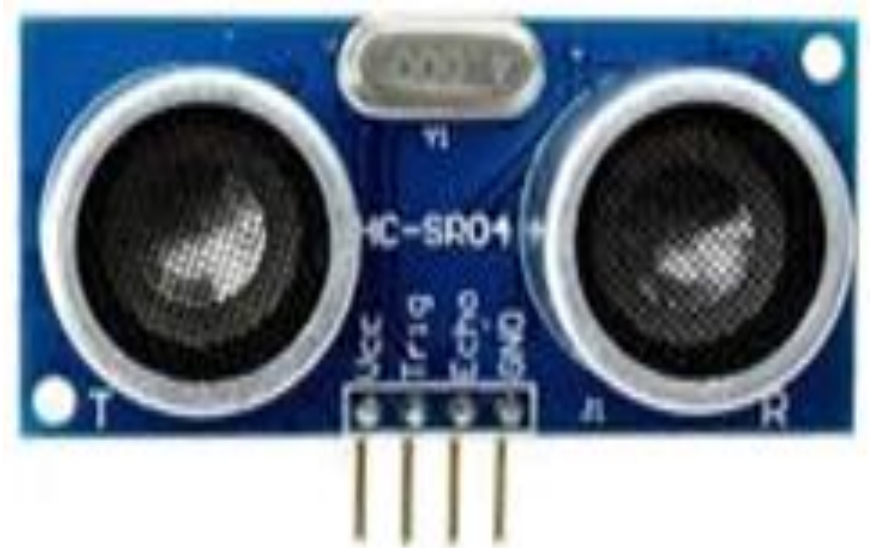

Fig.1. Ultrasonic sensor

Ultrasonic obstacle sensor comprises of a lot of ultrasonic recipient and transmitter which work at a similar recurrence. The sensor recognizes questions by transmitting a short ultrasonic burst and after that tuning in for the reverberation. Leveled out of a host microcontroller, the sensor discharges a short $40 \mathrm{KHz}$ blast under IC 555 Timer. This blast adventures or goes through the air, hits an article and after that skips by and by to the sensor. The sensor gives a yield heartbeat to the control unit with the estimation of detachment separation in LCD show and furthermore impels the pneumatic guard and slowing mechanism.

\section{PNEUMATIC CYLINDER}

Pneumatic cylinder consists of

A) Piston

B) Cylinder

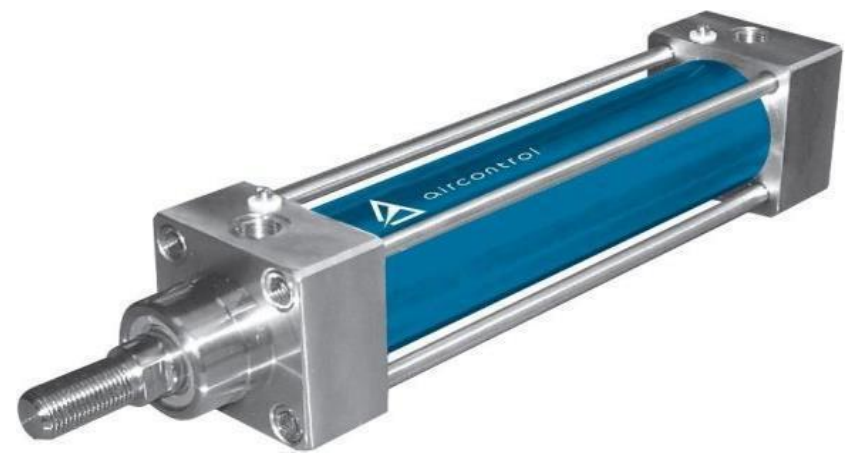

Fig.2. Double acting pneumatic cylinder
The cylinder we use is Double acting chamber one, where the push or yield power is created in just a single course. They have a solitary port to enable compacted air to enter the chamber. They have a spring inside the chamber. The spring is situated between the front finish of the chamber and the cylinder (around the cylinder bar). In this plan, the cylinder bar broadens when packed air is provided to the chamber.

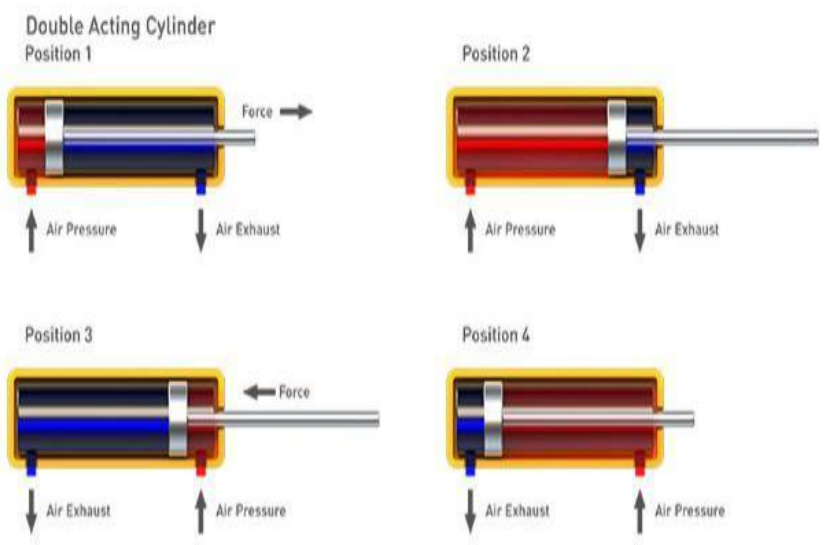

Fig.3. Working of pneumatic cylinder

As soon as the air supply is cut off, the piston rod retracts by spring force.

\section{DC MOTOR}

A DC motor is a device that converts electrical energy (direct current system) into mechanical energy. The basic working principle of a DC motor is: "whenever a current carrying conductor is placed in a magnetic field, it experiences a mechanical force".

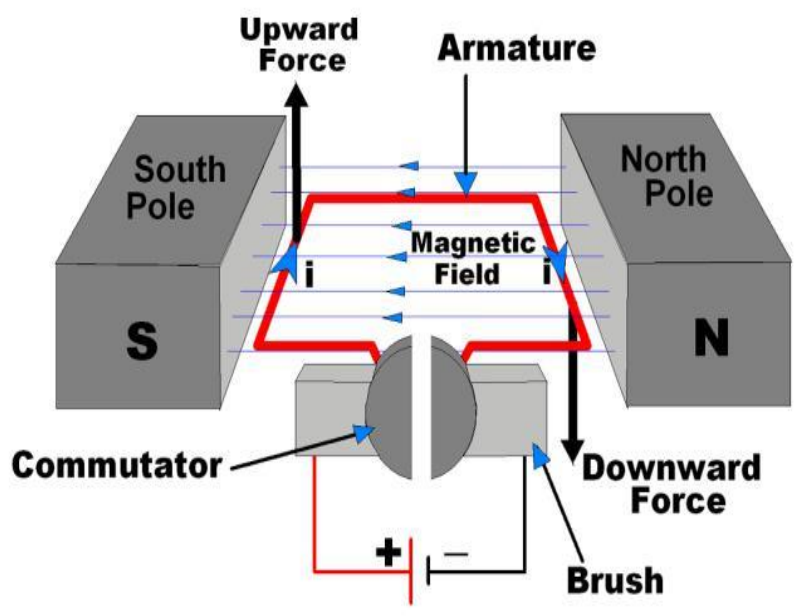

Fig.4. Working of DC motor

The essential segment of a DC engine is a current conveying armature which is associated with the stockpile end through the 


\section{International Journal of Engineering Applied Sciences and Technology, 2020 \\ Vol. 4, Issue 12, ISSN No. 2455-2143, Pages 305-309 \\ Published Online April 2020 in IJEAST (http://www.ijeast.com)}

commutator fragment and brushes. The armature is put between two lasting magnets which produce an attractive field. The motor is supplied from a battery and is used to drive the engine. Thus, it kick starts the whole setup.

\section{WORKING PRINCIPLES}

Using the supply from battery, the dc motor is turned on which drives the engine system. With the help of keypad, the sensing distance of ultrasonic sensor and activation of bumper and brake system is set. After the motor goes on, the Ultrasonic transmitter circuit begins to discharge short, highrecurrence sound heartbeats at customary interims. On the off chance that they strike an item, they are reflected back as reverberation sign to the recipient circuit of the sensor, which itself processes the separation to the objective dependent on the time-range between emanating the sign and getting the reverberation. The pulse time will vary depends on the closeness between the sensor and the object. Using this pulse timing the controller measures the distance. When the distance becomes low, the controller will switch ON the solenoid valve. The compressed air from the blower at the weight 40 pascal is gone through a polyurethane pipe associated with the Solenoid valve with one information The Solenoid valve has two yields and one information. The air entering the information goes out through the two yields when the planning control unit is incited. On the off chance that the solenoid valve is enacted, the packed air goes to the Double Acting Pneumatic Cylinder.

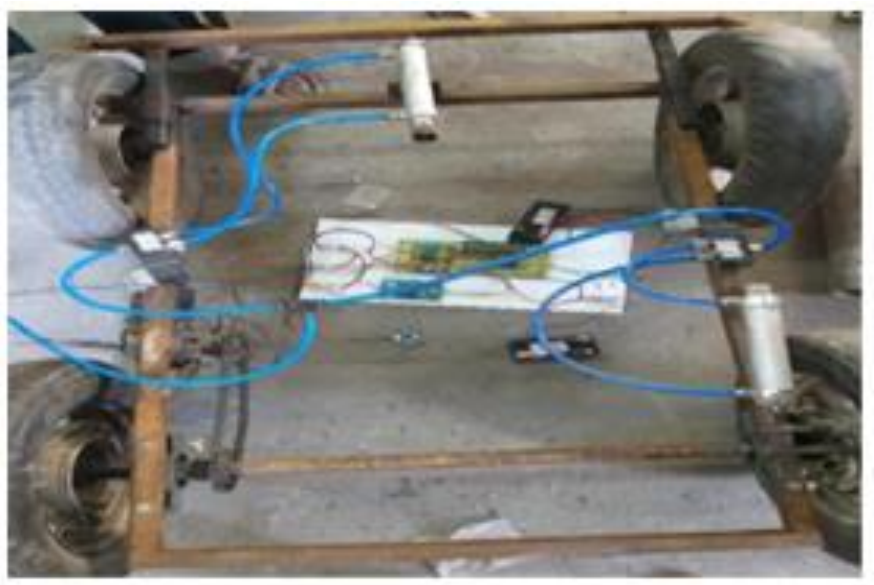

Fig.5. Hardware kit

When the compressed air activates the pneumatic cylinder, the solenoid valve allows the air to both pneumatic cylinders. Due to the high air pressure at the bottom of the piston in cylinders, the piston moves forward stroke and actuate the bumper or braking or both the systems. Before applying braking, the controller will display the alert in the LCD display. The braking course of action is utilized to brake the wheel bit by bit or all of a sudden because of the cylinder development. The braking pace is shifted by modifying the
Flow control valve. The compacted air is made to course through the Polyurethane cylinder to the stream control valve. The solenoid valve is associated toward the finish of the stream control valve.

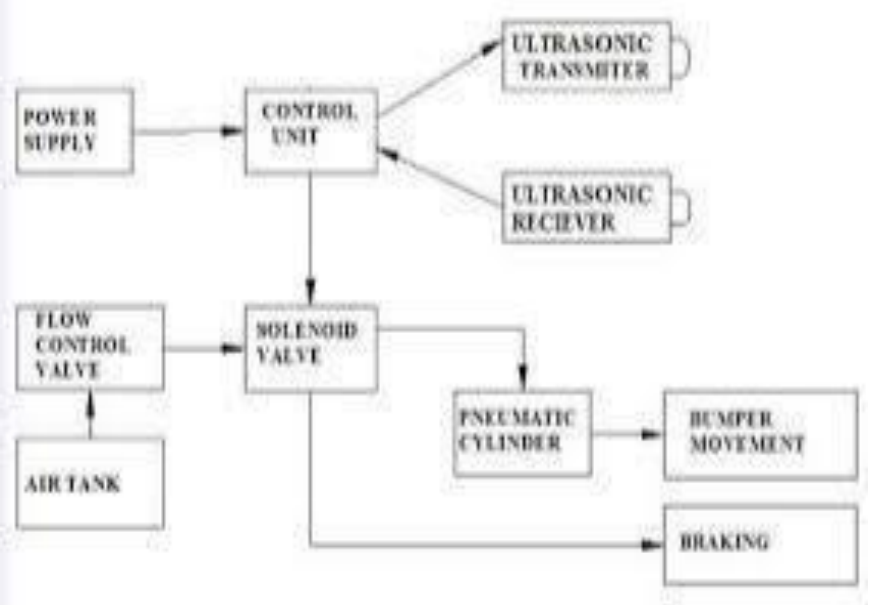

Fig.6. Flow diagram

\section{ADVANTAGES}

1. It able to Increase the firmness in braking system.

2. Very fast response in braking system.

3. System able to increase the safety before collision.

4. Less power consumption

5. Saves Life in road accidents.

\section{LIMITATIONS}

1. System has few limitations in overcrowded area.

2. Hard and thick materials cannot be fixed.

3. Due to the linkages the frictional losses occur.

4. Maintenance will be more since it has number of moving parts.

5. Moving parts.

\section{APPLICATIONS}

The system may be suitable for all types of light vehicles such as,

$$
\begin{array}{ll}
\text { - } & \text { Cars } \\
\text { - } & \text { Rickshaws } \\
\text { - Tempos }
\end{array}
$$

\section{Results And Discussions}

In our project, the main aim is to design and develop a control system based intelligent electronically controlled automatic bumper activation and braking system.

When the vehicle moves in a speed above the threshold level, the control unit gets activated by the command received 


\section{International Journal of Engineering Applied Sciences and Technology, 2020 \\ Vol. 4, Issue 12, ISSN No. 2455-2143, Pages 305-309 \\ Published Online April 2020 in IJEAST (http://www.ijeast.com)}

from ultrasonic sensor. By using keypad, we can set the sensing distance. Also, we use button to set speed LOW/HIGH. When user presses HIGH button, the bumper system will activate. The results are shown in the below fig 10.1 .

The ultrasonic collector circuit gets the reflected ECHO pulses and giving the control sign to the control circuit. The control circuit is utilized to enact the solenoid valve and stream control valve.

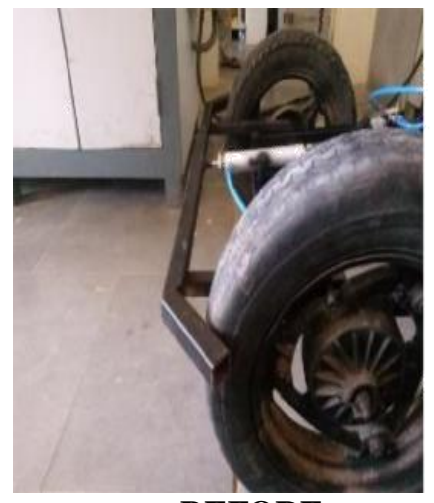

BEFORE

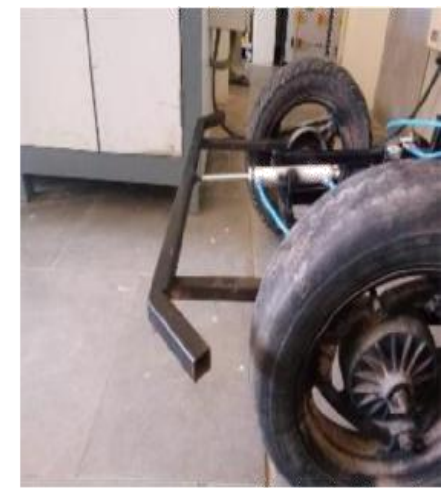

AFTER
Fig.7. Bumper activation system

By designing this system, we achieve low cost automation, reduce the braking effort $\&$ to increase the sureness of braking Application. Also, it provides pre-crash safety to passengers and minimizes the damage to the vehicle. The main objective to design this system is it works practically at low maintenance, low capital investment in less space.

When the user choses the LOW button, the braking system gets actuated. By following the same procedure above, the piston moves forward.

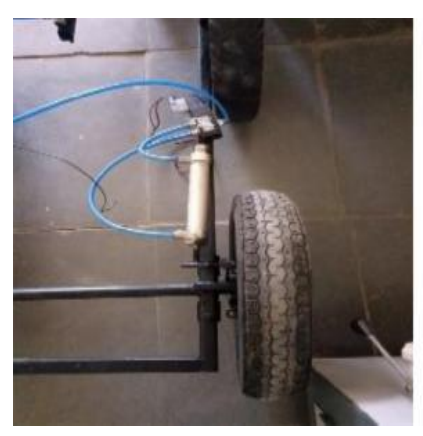

BEFORE

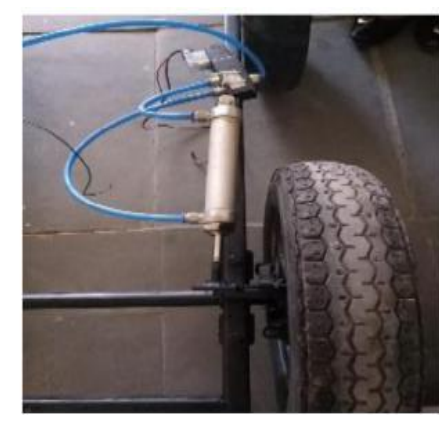

AFTER
Fig.8. Brake activation system

On the off chance that the solenoid valve is enacted, the compacted air goes to the Double acting Pneumatic chamber. The packed air actuates the pneumatic chamber and moves the cylinder.

\section{CONCLUSION}

The main aim is to improve the way for preventing the accidents and also reduce the risk from accidents like damage of vehicle, injury of humans, etc. The application of pneumatics produces smooth operation in braking system. The system can be disconnected with a switch thus the ride will be comfortable even in heavy traffic. In the end of our project work, we have developed a "DESIGN AND DEVELOPMENT OF AUTOMATIC PNEUMATIC BUMPER AND BRAKING SYSTEM" which helps to achieve low cost automation.

\section{FUTURE SCOPE}

The future work deals with incorporating this system with various different features to provide the further improvement in protection by the intelligent braking system in real time application. For that, some of the possible changes are:

1. Bumpers can be replaced by hydraulic bumpers.

2. Infrared sensors can sense eye blinking and give signal to solenoid valve when driver sleeps.

3. Bumper design can further be enhanced to act as external air bags.

\section{REFERENCE}

[1]. Aung,,D.(2018).Automatic Attendance System Using Speaker Recognition International Journal of Trend in Scientific Research and Development, 2(6),802806.

[2]. Automatic Emergency Braking System using Hydraulic Actuator for Preventing Road Accidents International Journal of Engineering and Advanced Technology,. 8(6),. 2967-2971.

[3]. Brännström,M., Coelingh,E. and Sjöberg,,J.(2014) Decision-making on when to brake and when to steer to avoid a collision International Journal of Vehicle Safety 7( 1),. 87,

[4]. Cho,O., Kim ,J.,and Kim,J.,(2016) Context-Aware High-Rise Structure Cracks Image Monitoring System Using Unmanned Aerial Vehicles International Journal of Control and Automation, 9, (9) $11-18$,

[5]. R,H.,(2019) Design and Fabrication of Sensor Operated Intelligent Braking System International Journal of Psychosocial Rehabilitation, 23. (3),.1-9,

[6]. katarkar,A., Rakshe,S., Pokharkar,S., Kute,V. and . Kale,T.,(2017)A Review Pneumatic Bumper For Four Wheeler Using Two Cylinder International Journal of Advance Engineering and Research Development,. 4, 
[7]. Lee,D.,(1976) A Theory of Visual Control of Braking Based on Information about Time-to-Collision Perception, 5,(4),. 437-459, .

[8]. Pavan Kumar, T.,Hemanth Krishna,R., Sai Krishna ,M.,and Meghana,J.(2018) Smart home system based on IoT International Journal of Engineering \& Technology, 7,. 500,.

[9]. . Rahate,P.,(2018) Experimental Work on Automatic Pneumatic Bumper International Journal for Research in Applied Science and Engineering Technology, 6, 2005-2010.

[10]. Rane,N., Wani,A., Chaudhari,V., and Fuse, C.,(2017) Review Paper on Automatic Braking System with Pneumatic Bumper International Journal of Advance Engineering and Research Development,. 4.

[11]. Sai,M. Edwin,E., Arun,M., Paul,S., and Sudarshan(2019), Train Collision Avoidance \& Crack Detection using GPS International Journal of Recent Technology and Engineering, 8, (25),153-157

[12]. Suryawanshi,M., Shelke M.,and Patil,M.(2017) Automatic Bottle Filling System using PLC. International Journal of Trend in Scientific Research and Development,. 1,. 1063-1065.,

[13]. O,T.,and O.,(2014)Estimation of The Atomic Radii Of Periodic Elements Using Support Vector Machine. Iinternational Journal of Advanced Information Science and Technology, 28,39-49,

[14]. Wada,P., Hiraoka ,M., and Doi,P.(2010) A Control Method of Deceleration Assistance System for Collision Avoidance based on Driver's Perceptual Risk. Industrial Robot An International Journal, vol. 37 , 